\title{
Erratum to: Geotechnical and geophysical characterization of the Bouira-Algiers Highway (Ain Turck, Algeria) landslide
}

Brahim Meziani $^{1,2} \cdot$ Djamel Machane $^{3} \cdot$ Abderrahmane Bendaoud $^{1}$.

Ghani Cheikh Lounis $^{1}$ - El-Hadi Oubaiche ${ }^{3}$ - Souhila Chabane ${ }^{1} \cdot$ Rabah Bensalem $^{3}$.

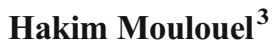

Published online: 21 March 2017

(C) Saudi Society for Geosciences 2017

Erratum to: Arab J Geosci (2017) 10:117

DOI 10.1007/s12517-017-2926-z

The original version of this paper was published with one misspelled author name and incomplete affiliation. Given in this article are the correct author names and complete affiliations.

The online version of the original article can be found at http://dx.doi.org/ 10.1007/s12517-017-2926-z.

Brahim Meziani

mezyaniibrahim@gmail.com

1 Département de Géologie, Faculté des Sciences de la Terre, de Géographie et de l'Aménagement du Territoire (FSTGAT) - USTHB, BP. 32, El Alia, 16111 Bab Ezzouar, Alger, Algeria

2 LNHC, Unité Bouira-Tour $n^{\circ} 7$ cité 1100 logements, Bouira, Algeria

3 Centre national de recherche appliquée en génie parasismique (CGS), 1 Rue Kadour Rahim, B.P. 252, Hussein Dey, Algiers, Algeria 